\title{
Erratum to: UV-Absorption and Silica/Titania Colloids Using a Core-Shell Approach
}

\author{
Liang Zhou • Hendrik Heinz • Mark D. Soucek • \\ Elvin A. Alemán • David A. Modarelli
}

Published online: 24 July 2010

(C) Springer Science+Business Media B.V. 2010

\section{Erratum to: Silicon}

DOI 10.1007/s12633-009-9030-2

The original version of this article unfortunately contained a mistake. The authors had mislabeled the axes of Figure 11 and Figure 12 of the article. The correctly labeled Figure 11 and Figure 12 are presented below.

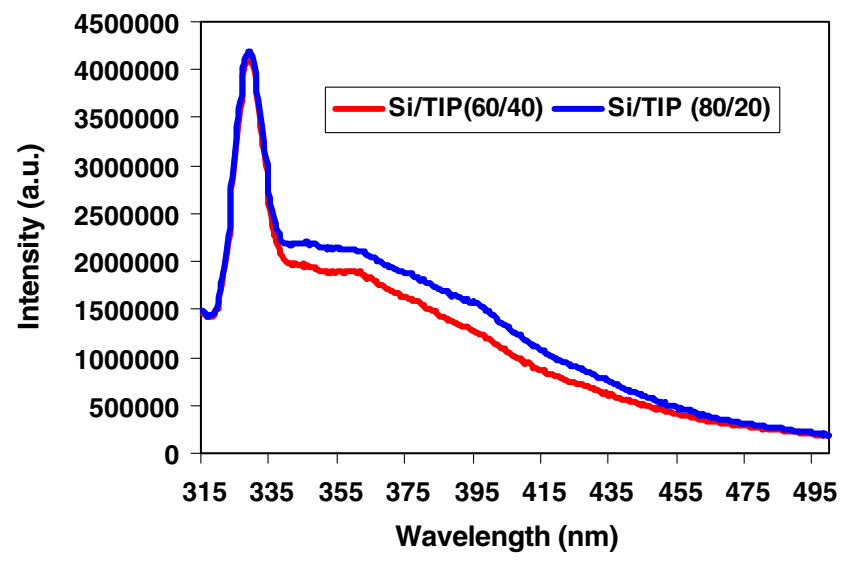

Fig. 11 Photoluminescence (PL) spectra of the Si/TIP system

The online version of the original article can be found at http://dx.doi. org/10.1007/s12633-009-9030-2.

L. Zhou $\cdot$ H. Heinz $\cdot$ M. D. Soucek $(\triangle)$

Department of Polymer Engineering, University of Akron,

Akron, OH 44325, USA

e-mail: msoucek@uakron.edu

E. A. Alemán • D. A. Modarelli

Department of Chemistry and The Center for Laser and Optical Spectroscopy, University of Akron,

Akron, OH 44325-3601, USA

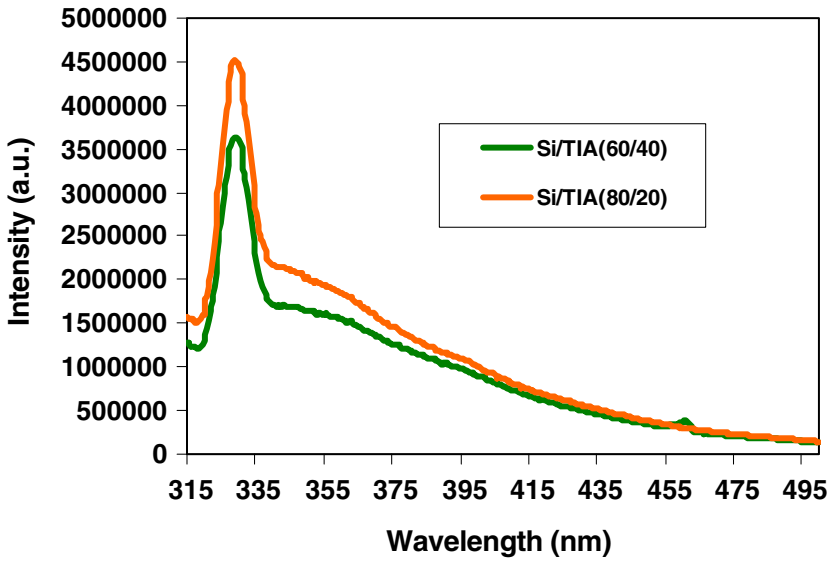

Fig. 12 Photoluminescence (PL) spectra of the Si/TIA system 